\title{
Corrigendum
}

\section{Ingredient bundles and recipe tastings in food pantries: a pilot study to increase the selection of healthy foods - CORRIGENDUM}

\author{
Emma C Stein ${ }^{1}$, Kristen Cooksey-Stowers ${ }^{2}$, Michelle L McCabe ${ }^{3}$, Marney A White ${ }^{1}$ and \\ Marlene B Schwartz ${ }^{2}$ \\ ${ }^{1}$ Yale School of Public Health, 60 College Street, New Haven, CT 06510, USA: ${ }^{2}$ University of Connecticut, Rudd \\ Center for Food Policy \& Obesity, Hartford, CT, USA: ${ }^{3}$ The Council of Churches of Greater Bridgeport, Bridgeport, \\ $\mathrm{CT}$, USA
}

doi: 10.1017/S1368980019000259, Published online by Cambridge University Press, 19 March 2019

\section{Original text and correction:}

The order of the authors was incorrectly listed; please find the updated version below.

\section{ORIGINAL TEXT (page 1)}

Emma C Stein1,*, Marlene B Schwartz2, Kristen Cooksey-Stowers2, Michelle L McCabe3 and Marney A White1

1Yale School of Public Health, 60 College Street, New Haven, CT 06510, USA: 2 University of Connecticut, Rudd Center for Food Policy \& Obesity, Hartford, CT, USA: 3 The Council of Churches of Greater Bridgeport, Bridgeport, CT, USA

\section{CORRECTION}

Emma C Stein1,*, Kristen Cooksey-Stowers2, Michelle L McCabe3, Marney A White1, Marlene B Schwartz2

1Yale School of Public Health, 60 College Street, New Haven, CT 06510, USA: 2 University of Connecticut, Rudd Center for Food Policy \& Obesity, Hartford, CT, USA: 3 The Council of Churches of Greater Bridgeport, Bridgeport, CT, USA

\section{Reference}

Stein EC, Cooksey-Stowers K, McCabe ML, White MA \& Schwartz MB. Ingredient bundles and recipe tastings in food pantries: a pilot study to increase the selection of healthy foods. Public Health Nutrition, 1-6. doi: 10.1017/S1368980019000259. 